\title{
СУБЪЕКТНО-ЛИЧНОСТНЫЕ ДЕТЕРМИНАНТЫ ИННОВАЦИОННОЙ АКТИВНОСТИ СПЕЦИАЛИСТОВ СЛОЖНЫХ ТЕХНИЧЕСКИХ СИСТЕМ
}

Водопьянова Н.Е., Никифоров Г.С., Старченкова Е.С., Столярчук Е.А. (Санкт-

Петербургский государственный университет, Санкт-Петербург, Россия) vodop@mail.ru professional.psychology@spbu.ruesto@yandex.ru sestar@yandex.ru

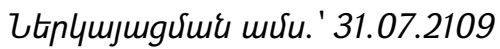

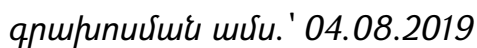

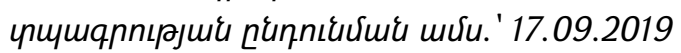

Разработка сложных технических систем (СТС) требует высокой инновационной активности инженерных кадров. Цель исследования - выявление субъектно-личностных детерминант инновационной активности и готовности к инновациям специалистов СТС. Выборка: специалисты проектной деятельности по созданию оборудования военно-промышленного назначения в количестве 50 человек. В результате эмпирического исследования проанализированы компоненты инновационной готовности, их взаимосвязи с обобщенной инновационной диспозицией, когнитивными стилями. Определены субъектно-личностные детерминанты инновационной готовности в зависимости от стажа работы в области проектирования СТС. Результаты: предикторами инновационной активности специалистов СТС являются следующие субъектные характеристики: мотивационные факторы к профессиональной самореализации, ответственность за инновацию, повышенная степень самоорганизации, потребности в компетентности и автономии деятельности, высокая самодетерминация в карьере.

Ключевые слова: инновачионная активность и готовность, субъектноличностные детерминанты, самоорганизация и самодетерминация.

Инновационное развитие экономики предопределяет глобальную интеллектуализацию современной экономической системы, когда знания, информация, квалификация работников превалируют над капиталом. В этих условиях особо востребован творческий, новаторский труд, способный поддерживать непрерывное развитие и высокую конкурентоспособность организации, обеспечивать рост национальной экономики, общественный прогресс.

НИИ и конструкторские бюро являются ведущими разработчиками и производителями мобильных робототехнических комплексов и транспортно-манипуляционных систем, что делает их деятельность важной для различных сегментов рынка. В настоящее время особо актуальна задача по интеллектуализации сложных технических систем. Решение задачи по созданию новых устройств и систем возложено на специалистов различного профиля. Сегодня от них требуется не 
просто высокая профессиональная компетентность, а целенаправленная и во многом «сверхнормативная» творческая активность [1, 27].

При этом наряду с созданием новых продуктов инженеры оказываются объективно включенными и в другой инновационный процесс - нововведения, происходящие «внутри» самой сфреры их профрессиональной деятельности. В данном контексте под инновациями мы понимаем изменения в формах организации работы инженеров и управлении инженерными разработками, использование новых средств исследования, проектирования и т.д. (отличая их от собственно инженерного творчества). Такие инновации неизбежны, но могут вести к различным результатам.

С одной стороны, следствиями организационно-профессиональных изменений могут стать значительное повышение продуктивности труда и технологические прорывы (во многом за счет активизации «предметной» креативности инженеров). С другой стороны, итогом инноваций часто оказывается разрушение коллективов с утратой наработанного годами потенциала, резкое падение качества работы и стремления к творческой самореализации собственно в ходе решения технических проблем.

Второй «эффрект» представляется недопустимым в свете значительной капиталоемкости современных технических разработок, например, в сфере космоса, авиации, энергетики, биотехнологий и одновременно, поэтому крайне высокая цена возможных ошибок в проектировании и реализации технических идей: как в плане соответствия требованиям заказчиков и потребителей, так и с точки зрения обеспечения безопасности.

Специфика работы в области сложных технических систем (СТС) заключается в конструкторской, технологической, материально-технической разработке и организационной подготовке к производству нового изделия мехатроники и робототехники. СТС- такое устройство (конструкция) которая обладает свойствами нелинейности, гетерогенности, частичной стохастичности, неопределённости, петлями обратной связи и т.д. Специалисты СТС участвуют в инновационной детятельности на этапе создание инноваций. Сложность деятельности специалистов СТС связана с высокими требованиями к творческой (инновационной) активности, на стадии фундаментальных исследований - с поиском идей, на последующих стадиях: прикладные исследования - с анализом и переработкой большого объема информационнотехнической документации; разработкой проектного образца (экспериментом) - с мотивационной и организационно-волевой устойчивостью для доработки проектов до их реального внедрения в производство. Разработка сложных технических систем (СТС) требует высокой инновационной активности инженерных кадров.

Инновационную активность мы рассматриваем с позиции системного и деятельностного подходов. Деятельностный подход является одним из самых разработанных в отечественной психологии во многом благодаря работам С. Л. 
Рубинштейна и А.Н. Леонтьева и который позволяет нам учитывать такой аспект деятельности как ее инновационность [2].

Актуальность исследования инновационной активности вытекает из высокой значимости в мировом масштабе инновационной проблематики, с которой справедливо связываются важнейшие ожидания как научно-исследовательского, так и практического характера. Проблемой исследования является недостаточная изученность способов управления инновационной активностью высоко профессионального персонала, путей оптимизации творческой деятельности, нацеленной на инновационное развитие предприятия на этапе создания инновации: фундаментальные и прикладные исследования, разработка (проектирование).

Практическая значимость исследования: результаты исследования могут быть использованы при подборе в инновационные группы организации, которая планирует массовое внедрение инноваций.

Цель исследования - выявление субъектно-личностных детерминант инновационной активности и готовности к инновациям специалистов СТС на этапе создания инновационной продукции.

Главная гипотеза исследования. Тип готовности к инновациям связан с ведущими факторами мотивации при работе в организации. При активной готовности к инновациям преобладают мотивационные факторы, при пассивной готовности к инновациям в мотивационной структуре преобладают гигиенические факторы.

Частные гипотезы исследования: 1. Удовлетворение базовых потребностей отражается на типе инновационной готовности. У сотрудников с активной готовностью к инновациям уровень удовлетворения выше, чем у сотрудников с пассивной готовностью к инновациям. Существуют различия между мужчинами и женщинами в их готовности к инновационной активности, мужчины больше проявляют такую готовность.

Методы и методики исследования. Для оценки типов готовности к инновациям методика «Оценка типа готовности к инновациям» И.О. Загашева; для оценки уровня удовлетворения базовых потребностей тест «Базовые потребности» Деси и Райана в адаптации Т.Д. Василенко; для определения инновационного мышления когнитивный стиль (адаптор - инноватор) «Индикатор Киртона» (KAI) опросник М.Киртона; для определения структуры мотивации мотивационный тест Герцберга. При обработке эмпирических данных, полученных в процедурае исследования, были использованы математико-статистические методы обработки данных: описательная статистика, сравнительный анализ с использованием параметрического критерия t-Стьюдента для независимых выборок, корреляционный, факторный и регрессионный анализы.

Описание выборки. В исследовании участвовало 50 специалистов СТС НИИ, в возрасте от 24 до 65 лет, средний возраст 40 лет, мужчин 46\%, занимающиеся 
созданием инновационной продукции и работающие в отделах: разработки, конструирования, исследования материалов, измерительной техники и сборки.

Результаты исследования и их обсуждение. Изучение отношения к инновациям проводилось по методике И.О.Загашева, определяющей выраженность готовности к инновациям по следующим типам: последовать за лидером (I), при условии материального вознаграждения (II), при условии возможности взять на себя ответственность за инновацию (III), при условии профессиональной самореализации (IY), при условии отсутствия серьезных изменений (Y), на основании прошлого опыта (YI), на основе позитивного эмоционального восприятия всего нового (YII). По типам готовности к инновациям I, II, Y, YI у специалистов СТС полученные значения имеют средний уровень выраженности. По типам: III, IY, YII наблюдаются высокие средние значения, что свидетельствует о том, что специалистам СТС свойственна готовность при возможности взять ответственность за инновацию, при возможности профессиональной самореализации и на основании позитивного восприятия всего нового. Для анализа типов отношения к инновациям был проведен фракторный анализ. В результате фракторного анализа было выявлено два фактора, описывающих 73\% совокупной дисперсии, первый фрактор описывает 47,4\% общей дисперсии, а второй - 26,3\%. Условно факторы были названы «Активная готовность к инновациям» (АГИ), «Пассивная готовность к инновациям» (ПГИ). Результаты фракторного анализа представлены на рисунке 1.

Каждый из двух полученных компонентов отражает свой аспект готовности к инновациям. Первый фактор отражает «активную субьектную» готовность к инновациям, в него вошли типы: III, IV, VI, VII, а второй фрактор отражает «пассивную обьектную" готовность, то есть такиеспециалисты СТС, которые готовы поддерживать определенные инновации при определенных условиях, но не будут теми, кто будет непосредственно их реализовывать, в него вошли типы: I, II и V.

Рассмотрим первый фрактор «активная готовность к инновациям» (АГИ). На АГИ влияет четыре переменных, которые примерно одинаково сильно выражены. Это говорит о том, что специалисты СТС, готовые к инновациям с позиции акивных субьектов, активно берут ответственность за инновацию.Они профессионально самореализуются на основании прошлого опыта и позитивного восприятия всего нового.

Специалистоы СТС, имеющие «Пассивную готовность к инновациям» (ПГИ), влияют три фактора: следование за лидером, материальное вознаграждение и отсутствие серьезных. Тип готовности к инновациям при условии отсутствия серьезных изменений свидетельствует о том, что инновационно активный субъект деятельности обладает сознательной активной позицией, который поддерживает изменения на основе позитивного восприятия всего нового, но не будет готов к незначительным изменениям потому, что он готов к глобальным. 


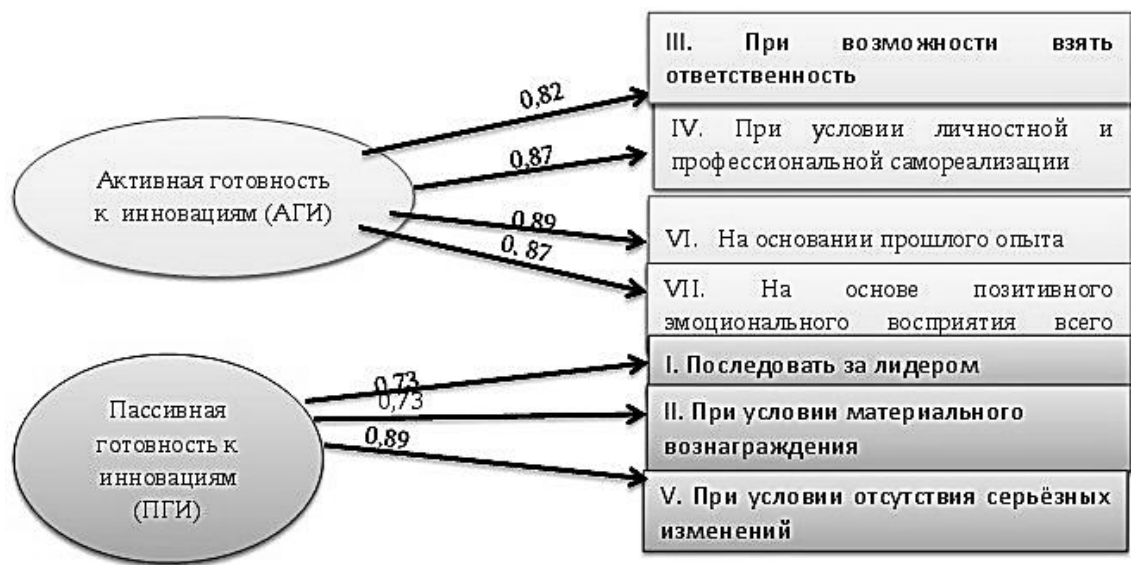

Рисунок 1. Факторный анализ типов готовности специалистов СТС

Таким образом, инновационноый активный специалист СТС должен обладать сознательной субьектной активной позицией и поддерживать изменения на основе позитивного восприятия всего нового, но он не будет готов к незначительным изменениям, а только к глобальным.

Полученные результаты показателей удовлетворения базовых потребностей по методике Деси и Райан специалистов СТС лежат в пределах средних значений, описанных в метдике: автономия 4,62, компетентность 4,82 и принадлежность 5,11. Достоверно значимых различий по стажу и полу не выявлено.

У специалистов СТС по методике «Индикатор Киртона» индекс когнитивного стиля KAl адаптор-иннноватор равен 94,22, что характеризует их поведение как слабовыраженных адаптаров. Они не предпочитают хорошо структурированные и стабильные условия работы, не любят совершенствовать существующие методы и практику, а предлагают такие пути выполнения заданий, которые можно реализовать, нарушая существующие традиции. Выявлена статистически значимая связь $(\mathrm{p}<0,05)$ индекса Киртона («акцептор-инноватор») со стажем и полом. У специалистов СТС с меньшим стажем работы наблюдается большая направленность в сторону инновационного мышления, по сравнению со специалистами, имеющими большой стаж. У мужчин средний показатель KAI достоверно выше $(98,25)$ по сравнению с женщинами $(87,72)$, что соответствует поведению слабовыраженных инноваторов. Им свойствено мыслить неординарно, ставить под сомнения общепринятые положения, решать задачи, заново определяя их или изменяя их условия, бросать вызов правилам, генерировать рискованные идеи и предлагать решения, которые не всегда приемлемы для большинства. У женщин данный показатель незначительно ниже среднего. Они более точны, надежны и методичны. Они предпочитают решать вопросы проверненными и понятными путями, внося 
улучшения и повышая эфрфективность, предлагая решения в большинстве случаев в соответствии с правилами и приемлемыми для большинства.

По методике определения структуры мотивации у специалистов СТС преобладают мотивы карьеры $(20,67)$ и достижение личного успеха $(21,11)$, а менее выражены - содержание работы $(13,78)$, общественное признание (15,74) и ответственность работы $(15,89)$; в целом доминируют мотивационные факторы $(71,44)$ по сравнению с гигиеническими факторами $(63,56)$. Достоверных различий по стажу и полу не выявлено.

Отсутствуют достоверные различия по активной и пассивной готовности между мужчинами и женщинами. Данные фракторы к активной и пассивной готовности к инновациям отражают субьектную готовность $к$ творческой активности. Можно утверждать, что мужчины и женщины одинаково готовы к внедрению инновацийи и к стаблиности функционирования. В настоящий период инновации и инновационная активность получают все большее распространение и одобрение во всех сорерах. В современных высокоинтеллектуализованных организациях ведется работа по избавлению от профессиональной половой дискриминации, особенно высокотехнологичных (инновационных) сферах. Поэтому мужчины и женщины одинаково включеаются в работу и им чаще всего транслируется одинаковое отношение. Возможно гендерные различия в данном случае уступают профессиональной рациональности, и мужчины и женщины одинаково относятся к творческой активности.

В результате корреляционного анализа выявлены следующие взаимосвязи. У специалистов СТС когнитивный стиль «адаптор-инноватор» положительно взаимосвязан с полом ( $r=0,28$ при $p=0,005)$ и активной готовностью к инновациям $(r=0,54$ при $p=0,001)$ и отрицательно со стажем ( $r=-0,30$ при $p=0,005)$. У специалистов СТС с высоким уровнем инновационного мышления наблюдается высокий уровень активной готовности к инновациям, но с увеличением стажа работы происходит снижение потребности к инновациям и доминируют структурированность деятельности и стабильные условия работы. Пассивная готовность к инновациям отрицательно взаимосвязана с базовой потребностью в автономии ( $r=-$ $0,27$ при $\mathrm{p}=0,05)$. При проявлении пассивной готовности к инновациям у специалистов СТС меньше выражена способность к осознанию, что при принятии решений они испытывают влияние других людей, что снижает их удовлетворенность в развитии и успешного функционирования. Специалисты СТС, демонстрирующие высокий уровень пассивной готовности к инновациям, меньше испытывают потребность в самостоятельном планировании рабочих задач, больше нуждаются в контроле и обратной связи со стороны руководства. Активная готовность к инновациям положительно взаимосвязана с мотивационными факторами: достижение успеха $(r=0,66$ при $p=0,001)$, карьера $(r=0,42$ при $p=0,001)$ и отрицательно с гигиеническими фракторами: фринансовыми мотивами ( $r=-0,47$ при 
$p=0,001)$, отношение с руководством ( $r=-0,37$ при $p=0,001)$. Пассивная готовность к инновациям положительно взаимосвязана с финансовым положением ( $r=0,36$ при $\mathrm{p}=0,005)$ и отрицательно с мотивационными фокторами: карьера ( $r=-0,28$ при $p=0,005)$ и ответственность в работе ( $r=-0,37$ при $p=0,005)$. Таким образом, инновационная готовность является различной у специалистов СТС, выделенных по ведущим типам мотивации при работе. Это доказывает существование взаимосвязи между исследуемыми переменными, то есть фактор готовности к инновациям оказывает влияние на мотивационную структуру.

В результате регрессионного анализа в случае величина R2 =0,46, то есть 46\% дисперсии переменных активная и пассивная готовность к инновациям обусловлена воздействием со стороны переменной мотивационные фракторы при $p=0,001$, что свидетельствует об очень высокой статистической достоверности полученных результатов. Уравнения линейной регрессии:

АКИ= 0,52 мотивационные факторы;

ПГИ= -0,4 мотивационные фракторы

Выводы. Субъектно-личностные детерминаны инновационной активности специалистов СТС - это мотивационные факторы к профессиональной самореализации, ответственность за инновацию, повышенная степень самоорганизации, потребности в компетентности и автономии деятельности, высокая самодетерминация в карьере. Выделено два фактора творческой готовности «Активная готовность к инновациям" и «Пассивная готовность к инновациям». Факторы творческой активности специалистов СТС предсказывают 46\% изменчивости двухфакторной структуры мотивов на этапе создания инновационного продукта. Обнаружена положительная связь между «Активной готовностью к инновациям» и инновационным мышлением. (адаптор - инноватор). Выявлена отрицательная связь между фактором «Пассивная готовность к инновациям» и удовлетворением базовой потребности в автономии. Мужчины и женщины рпавноценно включены в работу и ими транслируется равное отношение творческой активности.

\section{Литература}

1. Водопьянова Н.Е., Никифоров Г.С., Столярчук Е.А. Метакогнитивная регуляция как ресурс повышения интеллектуальной активности инженеров по робототехнике / материалы III-й Международной научно \практической «Личность, интеллект, метакогниции: исследовательские подходы и образовательные практики» 19-21 апреля 2018. Калуга. Россия. - С. 26 -34.

2. Водопьянова Н.Е., Старченкова Е.С., Столярчук Е.А. Интегративное развитие специалистов сложных технических систем / материалы международной научно-практической конференции «Психология труда и управления как ресурс развития общества в условиях глобальных изменений»" 26-29 сентября 2018. Тверь.- С. 285-292. 


\section{SUBJECT-PERSONAL DETERMINANTS OF INNOVATIVE ACTIVITY OF SPECIALISTS OF COMPLEX TECHNICAL SYSTEMS}

Vodopyanova N.E., Nikiforov G.S., Starchenkova E.S., Stolyarchuk E.A. (St. Petersburg State University, St. Petersburg, Russia)

The development of complex technical systems (ITS) requires highly innovative activity of engineering personnel. The purpose of the study is to identify the subjectpersonal determinants of innovation activity and readiness for innovations of ITS specialists. The object of study: employees of design activities for the creation of military-industrial equipment in the amount of 50 people. As a result of empirical research, components of innovative readiness were analyzed, their interrelations with generalized innovative disposition, cognitive styles. The subject-personality determinants of innovative readiness were determined depending on the length of service in the field of designing the JTS. Results: predictors of innovative activity of ITS specialists are the following subject characteristics: high motivation for professional self-realization, responsibility for innovation, an increased degree of self-organization and the need for competence and autonomy of activity, high self-determination.

Keywords: innovation activity and readiness, subject-personal determinants, selforganization and self-determination. 